First person objects, antipassives, and the political history of the Southern Kirant

Bickel, Balthasar ; Gaenszle, Martin

DOI: https://doi.org/10.1515/jsall-2015-0003

Posted at the Zurich Open Repository and Archive, University of Zurich ZORA URL: https://doi.org/10.5167/uzh-108942

Journal Article

Published Version

Originally published at:

Bickel, Balthasar; Gaenszle, Martin (2015). First person objects, antipassives, and the political history of the Southern Kirant. Journal of South Asian Languages and Linguistics, 2(1):63-86.

DOI: https://doi.org/10.1515/jsall-2015-0003 


\title{
Balthasar Bickel* and Martin Gaenszle First person objects, antipassives, and the political history of the Southern Kirant
}

\begin{abstract}
Several Kiranti languages (Tibeto-Burman, Nepal) from different genealogical sub-groups show multiple parallel developments from antipassive constructions with generic, non-specific objects into agreement markers registering first person objects. The developments span a relatively contiguous geographical area in the southernmost part of the family. We explain the developments by contact with politeness strategies of speaker-effacement in Maithili (Indo-Aryan) formal style, with which southern Kiranti elites have been in intense contact in about the same time frame as can be assumed for the emergence of the antipassive-based agreement forms. These findings illustrate a particularly tight interaction between natural (functional) strategies of politeness with specific historical contingencies.
\end{abstract}

Keywords: language contact, areal diffusion, antipassives, politeness, object agreement

DOI 10.1515/jsall-2015-0003

\section{Introduction}

Research on historical processes in linguistics is often trapped into debates on whether a specific development is caused by spontaneously occurring, 'natural' (or 'functional') processes or by contact effects triggered by the contingencies of sociolinguistic history. On closer inspection, however, the real interest lies in the precise interaction of these two forces. The present paper is a case study on such an interaction, showing how natural, possibly universal, processes that lead to parallel and unrelated developments in many languages interact with local contact effects that lead to highly specific developments limited to a narrow sociolinguistic situation.

Our focus is on a potential micro-area, the Southern Kirant (Nepali Kirã $t$ ). This is a sociolinguistic region in Southeastern Nepal, dominated by languages of

*Corresponding author: Balthasar Bickel: University of Zürich. E-mail: balthasar.bickel@uzh.ch Martin Gaenszle: University of Vienna. E-mail: martin.gaenszle@univie.ac.at 
the Kiranti subgroup of Tibeto-Burman. In the following, we will first give some background on the larger Kirant region, and the Kiranti group more generally (Section 2). We will then present a case of multiple parallel developments in the expression of first person objects in a geographically fairly contiguous area, expanding on earlier work by Ebert (1991) and Michailovsky (2001) (Section 3). In Section 4 we offer an explanation for these developments in terms of how natural processes interact with the local history of the region. Section 5 summarizes the results and concludes the paper.

\section{The Kirant: genealogy, geography, and typology}

The Kiranti group consists of about 30 languages (depending on how one counts), spoken in an area of just about $200 \times 100 \mathrm{~km}$ (Map 1). This high diversity of languages per area is typical of the Himalayas more generally, reflecting the effects of what Nichols (1997) calls an accretion zone. Like the Caucasus, the Himalayas form a typological enclave in Eurasia and as such, the region was largely unaffected by the large-scale spreads of structures that flattened the typological profiles of Eurasia (Bickel and Nichols 2003, 2005a,b). This is reflected by the fact that many Kiranti languages show features that are atypical of Eurasia, and also features that are atypical even on a world-wide scale.

Some of the most striking features of the Eurasian enclaves that characterize some or all Kiranti languages are: high degrees of verb inflectional synthesis, typically coupled with double agreement (with agents and patients in the case of transitive forms); prefixal morphology in parts of the system; inflectional possessive classes, typically more complex than just alienable vs. inalienable or kin vs. non-kin systems (Nichols and Bickel 2005); and deep-seated ergativity (across all tenses, unlike in Indo-Aryan) that has sometimes strict syntactic consequences, as for example in Belhare (Bickel 2004), and differs from Tibeto-Burman languages of Southeast Asia and Northeastern India (e.g., Chelliah 1997).

Rarities on a world-scale that characterize some Kiranti languages include, among others: free positioning of prefixes inside the grammatical word (Bickel et al. 2007a); recursive inflection and suffix copying, resulting in repeated occurrences of suffixes in verb compounds and verb derivations (Bickel et al. 2007a); locative cases distinguishing 'uphill', 'downhill' and other locations of a referent (Rai 1988, Bickel 1997, Ebert 1999); pronominal root distinctions for deictic transpositions (Bickel 2000, Schackow 2014); or articles sensitive to whether or not an adjective expresses color (Bickel 2003) or color and shape (Michailovsky 2007). Most of these features are not universal across the Kiranti group, reflecting once more the diversity and heterogeneity of the group. 


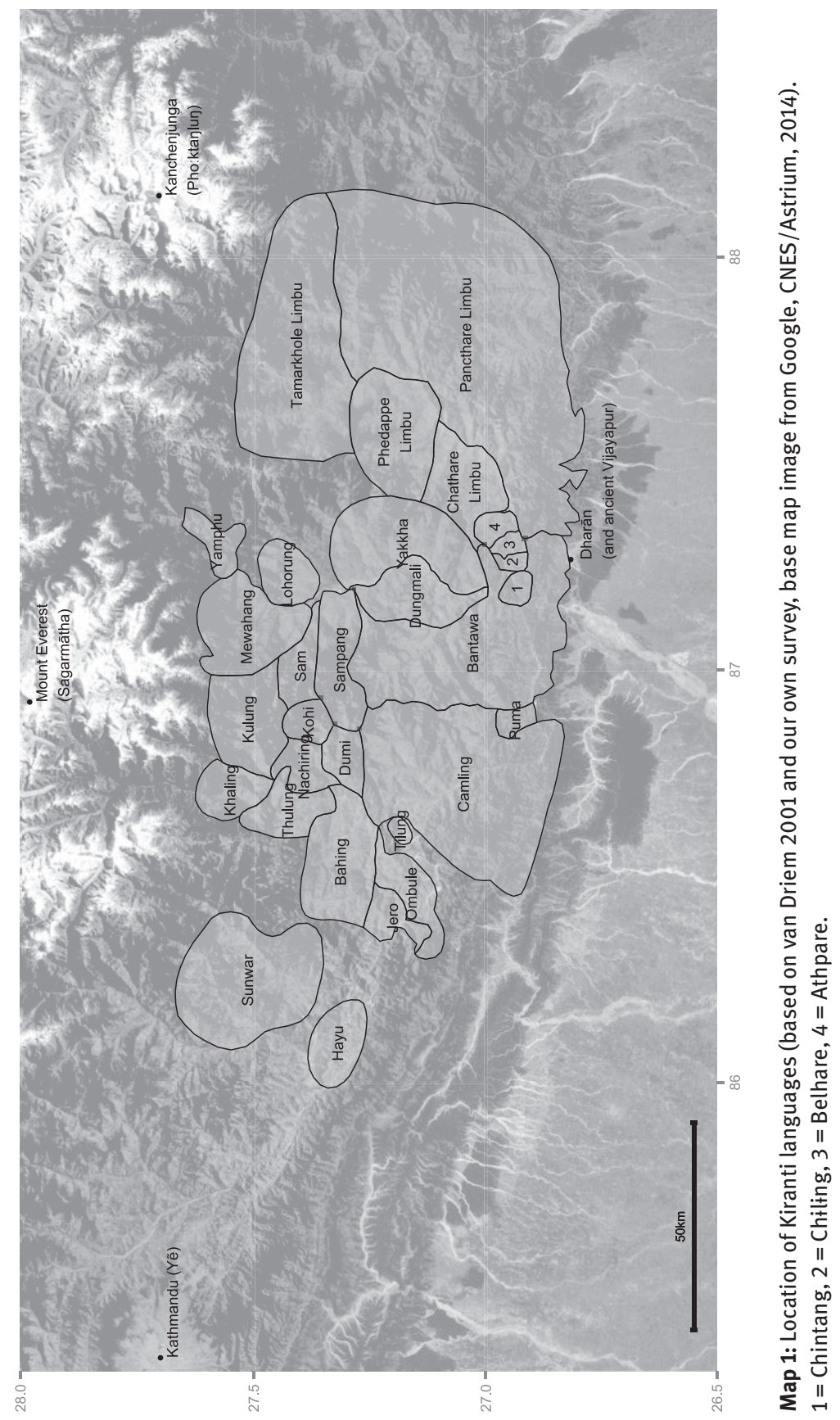


Against this background, the Kirant is not a region where one would expect strong signals of areal diffusion, not even on the small scale of micro-areas. Indeed, the sheer density of languages per square kilometer suggests that the history of the group was characterized by strong sociolinguistic compartmentalization and structural diversification resulting from this. Any case of areal spread is therefore surprising and demands close attention. In the following, we present one case of areal spread in the Southern part of the Kirant.

\section{Parallel developments in first person object marking}

In most Kiranti languages, transitive verbs agree with both $\mathrm{A}$ (agent) and $\mathrm{O}$ (object) arguments. ${ }^{1}$ In several cases, however, agreement with first person $\mathrm{O}$ arguments has been replaced by new forms that all involve a notion of impersonality, non-specificity and detransitivization. There are various variations on this theme and in the following we take them up in turn.

\subsection{First person object marking derived from a meaning of 'people'}

Earlier work by Ebert (1991) and Michailovsky (2001) has unearthed a micro-areal pattern in the Southeast of the Kirant in which the expression of first person objects is replaced in some parts of the paradigm by morphemes that ultimately go back to an etymon meaning 'person, human being, people' (gender-neutral). The pattern is illustrated by the following minimal pairs from Athpare and Limbu, where the (a) forms represent innovations and the (b) forms older forms that coexist, or at least coexisted until a few decades ago (and that have direct cognates in other Kiranti languages):

(1) Athpare (Ebert 1997b)
a. yan-lems-e
1eO-beat-PST
b. lems-i-n-e.
beat-1/2p-e
'S/he beat us (e)/me'
'S/he beat us (e).'

\footnotetext{
1 We use $\mathrm{A}$ and $\mathrm{O}$ for the syntactic roles that are typically associated with the most agent-like and the least agent-like role of multi-argument verbs. All other abbreviations follow the Leipzig Glossing Rules.
} 
(2) Maiwa-Mewa Limbu (Michailovsky 2001)

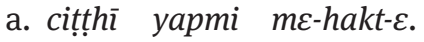
b. me-hakt-i-ge.
letter $1 \mathrm{eO}$ 3nsS-send-PST
3nsA-send-p-e
'They sent us (e) letters.'
'They sent it to us (e).'

The innovated forms, yay in Athpare and yapmi in Limbu, both derive from the Proto-Kiranti etymon *rak-mi 'person, human being'. The forms show a regular Eastern Kiranti development of initial * $r$ into $y$ (van Driem 1990), but they differ in the development of the coda of *rak: while in Athpare, the coda assimilated in nasality, in Limbu it assimilated in the place of articulation. In both languages, the relevant morphemes are also attested as indefinite markers. In Athpare, this use of yay is found in forms like yan-ka-pik [INDEF-PTCP-say] 'speaker, someone who says something' or yay-ka-ni-nin-ba [INDEF-PTCP-see-NEG-NMLZ] 'blind person, someone who doesn't see anything' (Ebert 1997b), a pattern also found in neighboring languages that do not otherwise show the use of yay for first person objects (e.g., in Belhare, see Bickel 1996). In Limbu, yapmi is a regular indefinite pronoun, with the morphosyntactic behavior of pronouns and not nouns; the full lexical meaning 'person' has been replaced by the noun mona məna, which is likely to be borrowed from an Indo-Aryan language in the neighborhood (Michailovsky 2001).

An essential feature of both developments is that the indefinite markers are prefixed to INTRANSITIVE forms, as shown by the absence of any further object agreement morphology (such as the suffix $-i$ for plural first person objects in the b-forms of the examples). In Athpare, the intransitivity of the forms is further evidenced by the behavior of nominalizing articles that can be attached to finite verb forms and that agree in number with the $\mathrm{S}$ or $\mathrm{O}$ arguments. Attached to older forms, as in (1b), the article reflects the nonsingular number of the object argument (lemsin-ga, where $=g a$ is nonsingular) while on new forms (1a), the article is in the singular, as if there was no object argument at all (yan-lem-ni=na [1eObeat-NEG=ART.SG], with singular =na) (Ebert 1997b).

This suggests that the immediate source of the new first person object forms is a construction with an indefinite or non-specific object followed by an intransitive verb form. Such a construction is in fact wide-spread and highly productive in the family (Bickel 2011). The construction is comparable to (and called here) ANTIPASSIVIZATION in that the A argument is in the nominative rather than the ergative case, and in that the object argument loses some of the properties that it normally has in regular transitive clauses: in some languages (such as in Puma) the object can no longer be case-marked under antipassivization, in some languages (such as in Belhare) it can no longer be extended by modifiers, and in yet others (such as in Limbu), it can no longer be dropped. What is shared by Kiranti 
antipassives is that they all cancel any commitment to the number or extent of the object referent, making this referent non-quantifiable, or if it is still quantifiable, non-specific or generic (Bickel et al. 2007b, Schikowski 2013).

This semantic property, which unifies all variants of the Kiranti antipassive, ${ }^{2}$ is they key to understanding the development of new first person object forms. We propose that the first step in the development of * $r a k-m i$ 'person, human being' into a first person object marker was in fact the use of the original noun in an antipassive environment where it was assigned non-quantifiable and nonspecific reference, i.e., a notion of 'people' in a generic sense rather than a specific person. The relevant bridge construction is still attested in Belhare, where the lexical noun ma?i 'person' (probably related to *rak-mi, cf. below) is found in antipassive constructions as well as in the function of a regular marker for first person (exclusive) objects. Consider the following contrasts:

(3) Belhare (Bickel 1996)

a. un-na mari niu-t-u.

(active)

3s-ERG person[sNOM] [3sA-]see-NPST-30

'S/he sees a (specific) person.' or 'S/he sees the person.'

b. un ma?i ni-yu. (antipassive)

3sNOM person[sNOM] [3sS-]see-NPST

'S/he sees people.' but not ${ }^{\star}$ 'S/ he sees the/a (specific) person.'

c. un-na ma?i-ni-yu. (first person object agreement)

3s-ERG eP-see-NPST

'S/he sees us (e).'

The contrast between (3a) and (3b) is between an active transitive and an antipassive form. The antipassive shows intransitive agreement morphology, nominative case on the A argument and induces a non-quantifiable, non-specific semantics for the object NP ma?i. The form in (3c) is nearly identical to the phrase [ma?i niyu] in the antipassive, except that it has been reanalyzed as a single grammatical word and is now a transitive verb form maPiniyu. The single

2 Note that we do not ascribe any theoretical importance to the term 'antipassive'. We use it only as a descriptive label for intransitively inflected multi-argument verbs that assign nominative rather than ergative to the most agentive argument and cancel any commitment to the number or extent of the object referent. See Bickel (2011) for extensive discussion of the typological and theoretical issues involved in this. 
word status is demonstrated by the fact that nothing can be inserted between the prefix and stem whereas in (3b), the object NP can be moved away (e.g., into a sentence-initial position; Bickel 2004); the status as a transitive form is demonstrated by the fact that the A noun phrase (here, a pronoun) is in the ergative in $(3 c)$.

\subsection{First person object marking derived from a meaning of 'all'}

An expanded survey of Kiranti languages shows that the very same pathway of development, from an antipassive construction to first person object forms, is also attested in two other sets of languages. However, the developments in these languages do not involve an etymon meaning 'person, people'. In one case, the antipassive involves instead a prefix $k h a-$, which goes back to a Proto-Kiranti

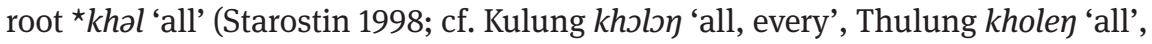
Khaling khöley 'all, everything') and ultimately to what is reconstructed as Proto-Tibeto-Burman *kul 'all' (Matisoff 2003; cf. WT kun, Garo khol khal, WB kun 'PL', Jingpho khūn). The other case, involves zero-marked antipassives with no further element. We first discuss developments involving kha- and come back to the zero-marked antipassives in Section 3.3.

Puma has a regular antipassive construction marked by kha-. This construction has replaced a subset of first person object agreement forms (specifically, all forms with a first person nonsingular inclusive reference and those forms with exclusive reference that combine with a second person A argument, but not $3>1$ e scenarios). If there are no further NPs, the resulting forms are ambiguous:

(4) Puma (Bickel et al. 2007b)
a. (kho-ci) som-kha-mı-tuk. (3-ns[NOM]) love-ANTIP-3pS-love.NPST 'They love people.'
b. (kho-ci-a) som-kha-ms-tuk.
(3-ns-ERG) love-1ns.i-3pA-love.NPST
'They love us (i).'

The antipassive with kha- contrasts with active forms in the same way as is known from other Kiranti languages and as we saw above, i.e., by canceling any commitment to the number or extent of object referents. A minimal pair, where the object is represented by the recipient of a verb of giving, is the following: 
(5) Puma (Bickel et al. 2007b)

a. yonni-lai chetkuma itd-u- $\eta$.

(active)

friend-DAT clan.sister give-3sP-1sA

'I gave my sister to a friend (in marriage).'

b. chetkuma kha-itd-on.

(antipassive)

clan.sister[sNOM] ANTIP-give-1sS.PST

'I gave away my sister (to someone/people).'

What is special about the kha-antipassive is that it is limited to human objects and that these human objects cannot be expressed by a separate noun: in (5b), for example, one could not insert even a highly general noun like mınna 'person' as an object. This constraint is not shared by a second antipassive form found in Puma, the $\emptyset$-antipassive, which has no special diathesis marking and behaves very similar to the antipassive construction found in languages like Belhare, as illustrated by (3b) above. In addition to this, the $\emptyset$-antipassive requires objects to be obligatorily overt. A minimal pair of the $\varnothing$-antipassive and its corresponding active form is the following (where the asterisk on the bracket indicates that the item is not optional):

(6) Puma (Bickel et al. 2007b)

a. $\operatorname{khim}(-\mathrm{lai}) \quad$ copp-u- $\eta$.

(active)

house-[s]DAT look.NPST-3sP-1sA

'I look at the/a house.'

b. *(khim) cop-na.

(antipassive)

house[sNOM] look-1sS.NPST

'I see houses.' or 'I do house-seeing.'

The ban against overt object NPs in kha-antipassives and the contrast in this to $\emptyset$-antipassives is explained by the etymology of the construction: the kha-form started out as a regular Ø-antipassive with * $k h a$ 'all' as its object, with no possibility of ellipsis. kha was likely a frequent object because its semantics fits the basic semantics of the antipassive construction as canceling more specific number specifications. As a result of this, the kha-antipassive cannot have additional object NPs even though the etymology is no longer transparent in Puma because in the meantime the original quantifier has been replaced by an Indo-Aryan loanword, jhara 'all'.

A critical step in this development was the incorporation of $k h a$ into the verb. This predicts that at some point, kha lost most of the properties that objects still have in Puma antipassives. The prediction is borne out by data on relativization. Whereas $\emptyset$-antipassivization allows relativization on the object, this property 
of objects is lost under kha-antipassivization. This is shown by the following grammaticality judgements, respectively:

(7) Puma (Bickel et al. 2007b)
a. [[uך-yonni
khip $=k u]$
1sPOSS-friend[sNOM]
[3sS-]read=NMLZ
kitap] [novel].
(Ø-antipassive)
book[sNOM] novel[sNOM]
'The kind of book that my friend reads is novels.'

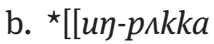 kha-dhe $=k u$ ]
1sPOSS-elder.brother[sNOM] ANTIP-beat=NMLZ
mınna] tıkku
(kha)
person[sNOM] DEM[sNOM]
Intended: 'These are the kind of people that my brother beats up.'

Forms for first person objects with $k h a$ - are also attested in other Kiranti languages. This has been noted for some varieties of Camling (Ebert 1991, 1997a) and Chintang (Bickel et al. 2007a). Unlike in Puma, however, these languages show no synchronic trace of $k h a$ - in antipassive function. In spite of this, it is reasonable to assume that the Camling and Chintang forms went through a stage of antipassive use that was similar to the one in Puma, though perhaps involving only a frequent collocation in discourse ( $k h a$ 'all' plus a $\emptyset$-antipassivized verb form) rather than fully-fledged univerbation. If this is indeed the history of the forms, it would explain why the results all build on intransitive verb forms. The intransitive structure would not be explained if kha had directly developed into an object marker. The intransitive nature of the kha-forms in Camling and Chintang is demonstrated by the paradigms in Tables 1 and 2. In each case, the upper paradigm represents the older forms, with regular object agreement. The lower paradigms represent the innovated kha-forms.

In both languages, $k h a$ - attaches to forms that are completely identical to the intransitive agreement forms displayed in the last column of the paradigms. No such identity is found in the older paradigms.

\subsection{First person object marking derived from $\emptyset$-antipassives}

In all languages reviewed so far, the development of new first person object forms was based on antipassives with an accompanying noun or quantifier (reflexes of 'person, people' or 'all'). But in most Kiranti languages antipassivization is also possible without overt object nouns (Bickel 2011), and so it is to be expected that 
Table 1: Camling past tense indicative paradigms with first person object and intransitive forms (with an abstract stem $\Sigma$ ): the top paradigm is from the Northwestern dialect, the lower paradigm from the Southeastern dialect. (Rows represent $\mathrm{A}$ agreement, columns 0 agreement. Grey-shading indicates forms judged impossible by speakers. Forms in brackets are attested only in elicitation but not in texts; Ebert 1997a).

\begin{tabular}{|c|c|c|c|c|c|c|}
\hline & $1 \mathrm{~s}$ & $1 \mathrm{de}$ & $1 \mathrm{pe}$ & $1 \mathrm{di}$ & $1 \mathrm{pi}$ & intransitive \\
\hline $2 \mathrm{~s}$ & 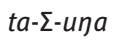 & \multirow[t]{3}{*}{$t a-\Sigma-c-k a$} & \multirow[t]{3}{*}{$t a-\Sigma-i-m-k a$} & & & $t a-\Sigma$ \\
\hline $2 d$ & $(t a-\Sigma-c i)$ & & & & & $t a-\Sigma-c i$ \\
\hline $2 p$ & $(t a-\Sigma-i)$ & & & & & $t a-\Sigma-i$ \\
\hline $3 s$ & \multirow[t]{3}{*}{$p a-\Sigma-u \eta a$} & \multirow[t]{3}{*}{$p a-\Sigma-c-k a$} & \multirow[t]{3}{*}{$p a-\Sigma-i-m-k a$} & \multirow[t]{3}{*}{$p a-\Sigma-c i$} & \multirow[t]{3}{*}{$p a-\Sigma-i$} & $\Sigma$ \\
\hline $3 d$ & & & & & & $\Sigma-c i$ \\
\hline $3 p$ & & & & & & $m i-\Sigma$ \\
\hline
\end{tabular}

\begin{tabular}{|c|c|c|c|c|c|c|}
\hline & $1 \mathrm{~s}$ & $1 \mathrm{de}$ & $1 \mathrm{pe}$ & $1 \mathrm{di}$ & $1 \mathrm{pi}$ & intransitive \\
\hline $2 \mathrm{~s}$ & \multicolumn{3}{|c|}{ kha-ta- $\Sigma$} & & & $t a-\Sigma$ \\
\hline $2 d$ & \multicolumn{3}{|c|}{ kha-ta- $\Sigma-c i$} & & & $t a-\Sigma-c i$ \\
\hline $2 p$ & \multicolumn{3}{|c|}{ kha-ta- $\Sigma-i$} & & & $t a-\Sigma-i$ \\
\hline $3 s$ & \multicolumn{5}{|c|}{ 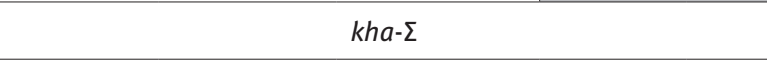 } & $\Sigma$ \\
\hline $3 d$ & \multicolumn{5}{|c|}{$k h a-\sum-c i$} & $\Sigma-c i$ \\
\hline $3 p$ & \multicolumn{5}{|c|}{ 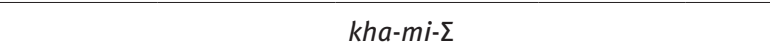 } & $m i-\Sigma$ \\
\hline
\end{tabular}

first person object forms could also have emerged from Ø-antipassives without any further morpheme. This is indeed what was recently discovered in Yakkha by Schackow (2014). Table 3 shows the modern Yakkha forms of first person object agreement in comparison with the intransitive forms. All first person object forms except those with singular reference have been replaced by intransitive forms. The source of the forms is intransitive singular forms, but they appear to have been expanded to cover any A argument. Older forms with explicit object agreement are attested in material from the 1980s, but the interpretation of the paradigms is not clear, as there seem to have been transcription and elicitation problems (see Schackow 2014: 219-220 for discussion.)

Like in other Kiranti languages, the intransitive agreement forms of multiargument verbs is regularly used as a $\emptyset$-antipassive in Yakkha. A minimal pair is given in (8) below. 
Table 2: Chintang paradigms with first person object and intransitive forms: the top paradigm is from the Eastern variety (Mulgãũ), the lower paradigm from the Western (Sāmbugãũ) variety. (Same conventions as in Table 1, but with both nonpast (upper entries) and past (lower entries) forms in each cell because they involve partially different affixes. Elements within curly brackets can freely permute; Bickel et al. 2007a).

\begin{tabular}{|c|c|c|c|c|c|c|}
\hline & $1 \mathrm{~s}$ & $1 \mathrm{de}$ & $1 \mathrm{pe}$ & $1 \mathrm{di}$ & $1 \mathrm{pi}$ & intransitive \\
\hline $2 \mathrm{~s}$ & $\begin{array}{l}a-\sum-m a-? \tilde{a} \\
a-\Sigma-e-h-\tilde{e}\end{array}$ & \multirow[t]{3}{*}{$\begin{array}{l}\{a-m a-\} \Sigma-c e-k e \\
\{a-m a-\} \Sigma-a-c e\end{array}$} & \multirow[t]{3}{*}{$\begin{array}{l}\{a-m a-\} \Sigma-n o \\
\{a-m a-\} \Sigma-e\end{array}$} & & & $\begin{array}{l}a-\Sigma-n o \\
a-\Sigma-e\end{array}$ \\
\hline $2 d$ & $\begin{array}{l}a-\Sigma-m a-P a-\eta-c \dot{t}-\eta \\
a-\Sigma-a-\eta-c \dot{t}-h \tilde{e}\end{array}$ & & & & & $\begin{array}{l}a-\Sigma-c e-k e \\
a-\Sigma-a-c e\end{array}$ \\
\hline $2 p$ & $\begin{array}{l}a-\Sigma-m a-P a-\eta-n \dot{-} \eta \\
a-\Sigma-a-\eta-\eta \dot{t}-h-\tilde{e}\end{array}$ & & & & & $\begin{array}{l}a-\Sigma-i-k i \\
a-\Sigma-i-h-\tilde{e}\end{array}$ \\
\hline $3 s$ & $\begin{array}{l}u-\Sigma-m a-P \tilde{a} \\
u-\Sigma-e-h-\tilde{e}\end{array}$ & \multirow[t]{3}{*}{$\begin{array}{l}m a-\Sigma-c e-k e \\
m a-\Sigma-a-c e\end{array}$} & \multirow[t]{3}{*}{$\begin{array}{l}m a-\Sigma-n o \\
m a-\Sigma-e\end{array}$} & \multirow[t]{3}{*}{$\begin{array}{l}\text { mai- } \Sigma-c e-k e \\
m a i-\Sigma-a-c e\end{array}$} & \multirow[t]{3}{*}{$\begin{array}{l}\text { mai- } \Sigma-n o \\
\text { mai- } \Sigma-e\end{array}$} & $\begin{array}{l}\Sigma-n o \\
\Sigma-e\end{array}$ \\
\hline $3 d$ & $\begin{array}{l}u-\Sigma-m a-P a-\eta-c \dot{-}-\eta \\
u-\Sigma-a-\eta-c \dot{t}-h-\tilde{e}\end{array}$ & & & & & $\begin{array}{l}u-\Sigma-c e-k e \\
u-\Sigma-a-c e\end{array}$ \\
\hline $3 p$ & $\begin{array}{l}u-\Sigma-m a-? a-\eta-n \dot{i}-\eta \\
u-\Sigma-a-\eta-n \dot{t}-h-\tilde{e}\end{array}$ & & & & & $\begin{array}{l}u-\Sigma-n o \\
u-\Sigma-e\end{array}$ \\
\hline
\end{tabular}

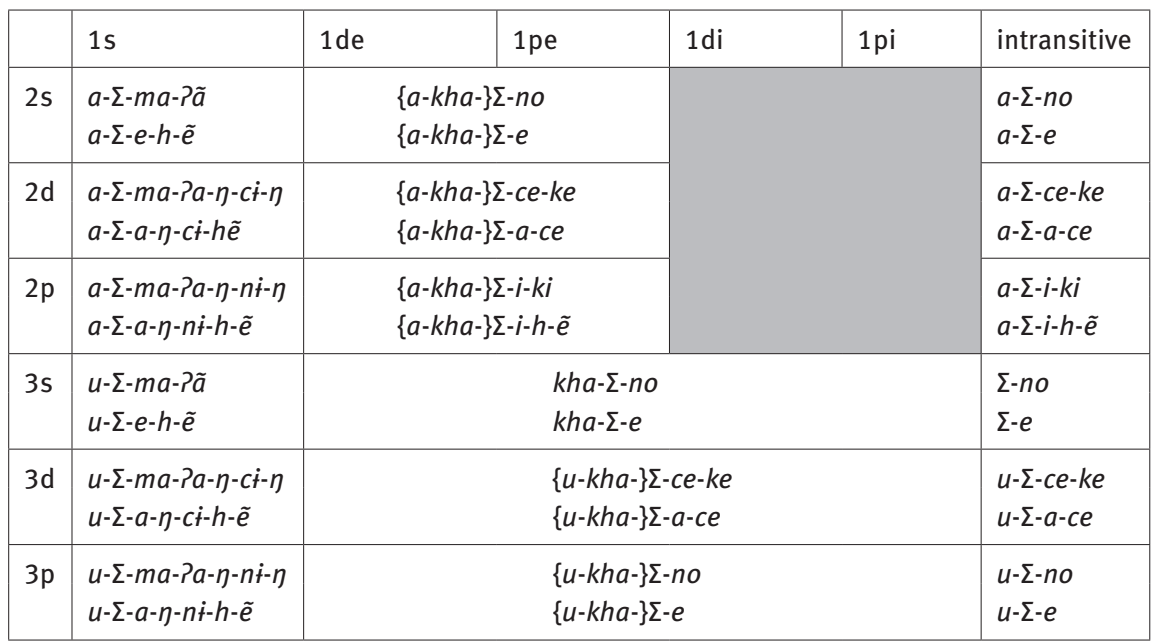


Table 3: Yakkha paradigm with first person object and intransitive forms (same conventions as in Tables 1 and 2; Schackow 2014).

\begin{tabular}{|c|c|c|c|c|c|c|}
\hline & $1 \mathrm{~s}$ & $1 \mathrm{de}$ & $1 \mathrm{pe}$ & $1 \mathrm{di}$ & $1 \mathrm{pi}$ & intransitive \\
\hline $2 \mathrm{~s}$ & $\sum-\eta-k a$ & \multirow{3}{*}{\multicolumn{2}{|c|}{$\Sigma-k a$}} & & & $\Sigma-k a$ \\
\hline $2 d$ & & & & & & $\Sigma-c i-k a$ \\
\hline $2 p$ & & & & & & $\Sigma-i-k a$ \\
\hline $3 \mathrm{~s}$ & $\Sigma-\eta$ & & \multirow{3}{*}{$\Sigma$} & & & $\Sigma$ \\
\hline $3 d$ & & & & & & $\Sigma-c i$ \\
\hline $3 p$ & & & & & & $n-\Sigma$ \\
\hline
\end{tabular}

(8) Yakkha (Schackow 2014)

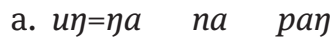
$\operatorname{cog}-u k s-u=n a$
(active)
$2 \mathrm{~s}=\mathrm{ERG}$ this house[NOM] do-PRF-3sO=ART.SG
'He has made this house.'
b. khatnin=go linkha ekdam cog- $a=n u \eta \quad \operatorname{cog}-a=n u \eta$. (antipassive) but=TOP a.clan very do-PST=COM do-PST $=\mathrm{COM}$ 'as the Linkha man worked and worked'

As (8b) shows, object nouns are not obligatory, but there is also no ban against them, as shown by the following antipassive construction with the overt object noun chemha 'liquor':

(9) Yakkha (Schackow 2014)

chemha un-me? $=n=e m$

liquor drink-NPST=ART.SG=ALTERNATIVE.Q

$\eta$-un-me? $=n=e m$ ?

NEG-drink-NPST $=$ ART.SG=ALTERNATIVE.Q

'Does she drink raksi (an alcoholic beverage type) or not?'

Yakkha differs from all other languages in that intransitively inflected forms of multi-argument predicates are also used in passive rather than antipassive function, resulting in ambiguity:

(10) Yakkha (Schackow 2014)
ochon $=h a$ cayonwa new=ART.NC food
pahile kulpitri $=c i$
m-bim-me.
'They give the new food to the ancestors at first.' or 'The ancestors are given the new food at first.' 
Schackow (2014) further observes that the passive interpretation often gives rise to a first plural A reading, as in the following:

(11) Yakkha (Schackow 2014)

kisa sis- $a=n a$

deer kill-PST=ART.SG

'The deer was killed.' or 'We killed the deer.'

Passive forms have not yet replaced regular transitive A forms in the paradigms and this development seems to be unique to Yakkha and unrelated to the development of $\emptyset$-antipassives into first person $\mathrm{O}$ forms.

\subsection{Genealogical and geographical distribution}

The three patterns observed above do not map directly onto genealogical trees based on sound laws and lexical data. Figure 1 shows a plausible tree of Kiranti, annotated for some of the key sound laws that motivate it (and that synthesize proposals by Michailovsky (1994), van Driem (2001), Opgenort (2004) and Bickel's ongoing survey work). ${ }^{3}$ The languages with first person forms based on antipassives are marked by boxes and keyed to the kind of object noun involved in the historical process: *rak-mi and ma?i 'person, people' (Limbu, Athpare, Belhare), or kha 'all' (Southeastern Camling, Puma, Sāmbugāũ Chintang), or none (Yakkha).

The developments cross-cut major subgrouping divisions. This suggests that the development did not arise in a single node but represents multiple parallel developments. This is confirmed by the fact that one and the same overall pattern shows distinct developmental details. The precise development of 'person,

3 Chintang and Puma data were not available for earlier proposals and Chintang was sometimes misclassified as Central Kiranti. The assignment of Chintang to Eastern Kiranti is evident from the aspiration of proto-preglottalized stops (as in phun 'flower', phak 'pig', thuy- 'drink', them 'what, which' etc.) and the partial merger of initial ${ }^{\star} r$ and ${ }^{\star} R$ with $y$ (before back vowels, as yum 'salt', yam 'body', yom- yop- 'weak, sick' etc. vs. ret- 'laugh' etc. $\prec{ }^{\star} R$; yokt- 'tremble' vs. rin 'language' etc. $\prec{ }^{\star} r$ ). The latter development contrasts with Limbu, where the merger of rhotics and $y$ is complete. The assignment of Puma to Southern Central Kiranti is chiefly based on the voicing for originally preglottalized initials (as in buywa 'flower', bok 'pig', dur- 'drink', dem 'how, what' etc.) and the merger of initial ${ }^{\star} R$ with $r$ (as in rum 'salt', ram 'body', rom-t- 'weak',

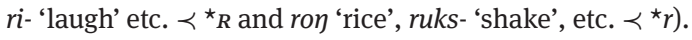




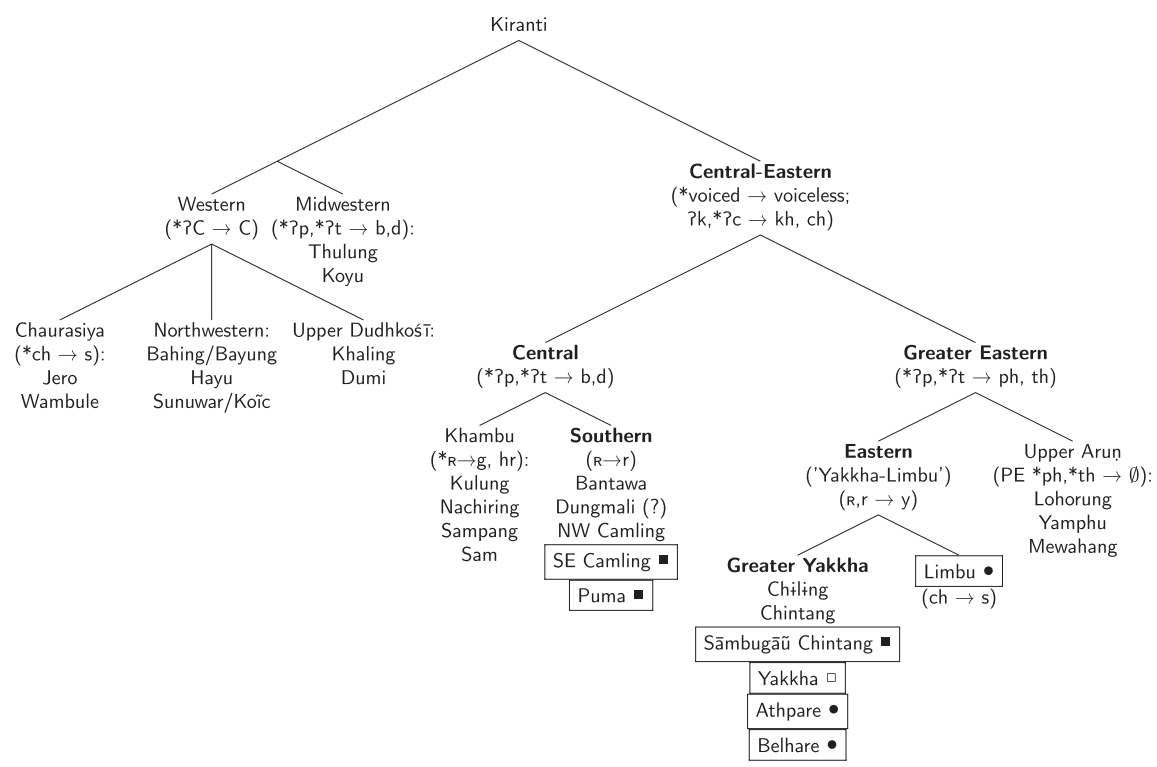

Fig. 1: Genealogy of Kiranti languages with sound laws supporting the topology. Languages in boxes show a development of antipassives into first person object markers, involving an object

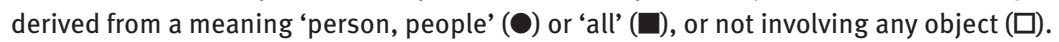

people' nouns is different in all three languages that show it: involving the full etymon * rak-mi in Limbu but only the first syllable in Athpare. The Belhare item ma?i is perhaps related to this, but with a different development. We lack an exact reconstruction, but we note a Chintang cognate ma?mi and a nasal-initial variant (napmi na:pmi) of yapmi in Limbu in some dialects (Michailovsky 2001, van Driem 1987) so that a kind of anticipatory long-distance assimilation in the onset (replacing $r$ by $m$ ) and reduction of the coda of *rak-mi (reducing $k$ to a glottal stop) is a plausible though unproven scenario.

In two cases, the developments cross-cut even languages. In the case of Camling the division appears to follow a major dialect boundary, which is also reflected in phonology and other properties of the language (Ebert 1997a). In Chintang, the innovated kha-forms are found among speakers in one part of the Chintang area (centered on Sāmbugāũ), but this does not necessarily reflect a full-fledged dialect cluster distinction. There are no major phonological distinctions associated with the kha-variety, and only two minor morphological distinctions, with differences in negation and imperfective markers (Bickel et al. 2007a, Schikowski 2013). 
Map 2 shows that the developments span an area that is geographically fairly contiguous. ${ }^{4}$ The only exceptions are Chiling and Bantawa, although in the case of Chiling we do not know whether the gap is real or apparent because the language is not described. For Bantawa, Doornenbal (2009) describes an antipassive with kha-, working in similar way to Puma. But there is no trace of this antipassive having developed into first object forms.

Outside of this area, we have not come across any parallel development in any of the Kiranti languages that have been described in the literature. Ebert (1991) cites a case from Dungmali, a language spoken between Yakkha and Chintang, and this would fit with the areal distribution in Map 2. However, as the language has not yet been sufficiently documented, we refrain from a historical interpretation of its agreement morphology.

Given the overall distribution in Map 2, we propose that the developments represent areal diffusion in the Southern Kirant. The only piece of evidence that would speak against this, is the observation that Bantawa lacks the relevant developments. However, based on local oral history, there is good reason to assume that Bantawa has moved into the South and especially into the Mahābhārat hill track only recently. It is likely that just a few generations ago these regions were occupied by speakers of other Kiranti languages that do show the innovated forms.

Puma and Belhare are the only languages where we find no trace whatsoever of older forms that were used in those places where antipassives took over. This suggests that these two Southern languages were the centers of innovation, once for 'all'-based developments (the Puma kha-antipassives in the west) and once for 'people'-based developments (the Belhare ma?i-construction in the east). However, it is possible that there was a still earlier innovation, centered again in the South, but now involving Belhare and Chintang rather than Belhare and Puma. Belhare and Chintang, and no other documented languages, have markers $m a$ - and mai-for first person objects. In Chintang, Table 2 shows that $m a$ - is found with exclusive, mai- with inclusive object reference. The Belhare forms are given in Table 4. Here, both mai- and ma- have singular object reference and mai- is analyzed as an allomorph of $m a$ - by Bickel (1996). These differences in the exact synchronic distribution notwithstanding, it is possible that both markers continue the same line of development from the noun for 'people' ${ }^{\star}$ rak-mi $\succ{ }^{\star}$ napmi (cf. Phedāppe Limbu, possibly via ${ }^{\star}$ yapmi) $\succ{ }^{\star}$ mapmi $\succ{ }^{\star}$ ma?mi (Chintang) $\succ$ ma?i(-) (Belhare) $\succ m a i-\succ m a-$.

4 Note hat the Southeastern Camling and Limbu areas are our guesses only. We are not aware of any detailed dialect-geographical surveys of the extent to which kha- and rakmi-based agreement is found across the relevant areas. 


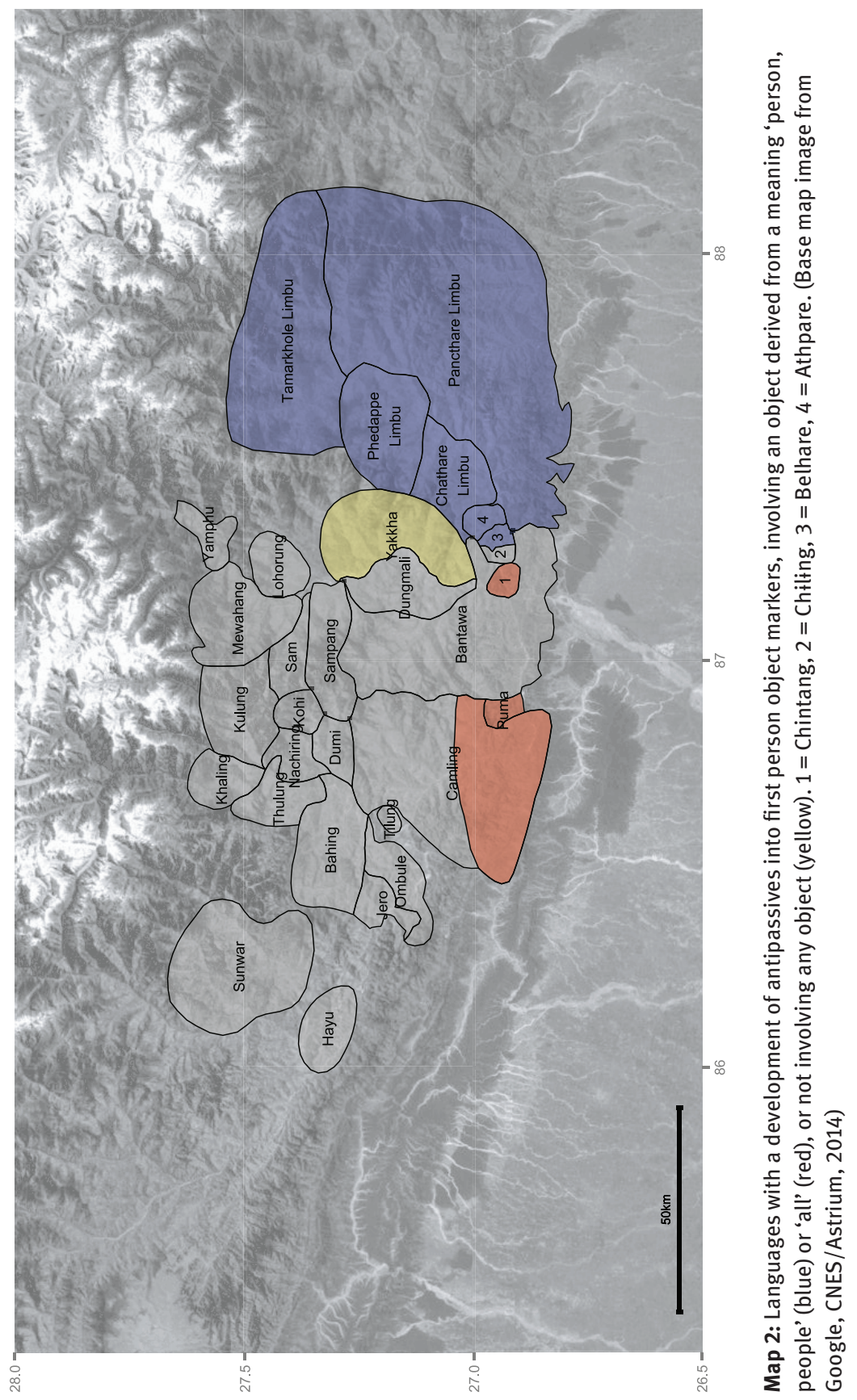


Table 4: Belhare paradigms with first person object and intransitive forms ( $N$ is a floating nasal feature that attaches to preceding codas or, if there is none, is realized as a syllabic nasal; Bickel 1996).

\begin{tabular}{|c|c|c|c|c|c|c|}
\hline & $1 \mathrm{~s}$ & $1 \mathrm{de}$ & $1 \mathrm{pe}$ & $1 \mathrm{di}$ & $1 \mathrm{pi}$ & intransitive \\
\hline $2 \mathrm{~s}$ & $k a-\Sigma-k a$ & \multicolumn{2}{|c|}{$m a P i-\Sigma-k a$} & & & $\Sigma-k a$ \\
\hline $2 d$ & $k a-\Sigma-c h i-k a$ & \multicolumn{2}{|c|}{ maPi- $\Sigma-c h i-k a$} & & & $\sum$-chi-ka \\
\hline $2 p$ & $k a-\Sigma-i-k a$ & \multicolumn{2}{|c|}{$m a P i-\Sigma-i-k a$} & & & $\sum-i-k a$ \\
\hline $3 \mathrm{~s}$ & mai- $\Sigma$ & \multicolumn{2}{|c|}{ mari- $\Sigma$} & \multicolumn{2}{|c|}{$k a-\Sigma$} & $\Sigma$ \\
\hline $3 d$ & $m a-\eta-\Sigma-c h i$ & \multicolumn{2}{|c|}{ 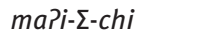 } & \multicolumn{2}{|c|}{$k a-\eta-\Sigma-c h i$} & $N-\Sigma-c h i$ \\
\hline $3 p$ & $m a-\eta-\Sigma$ & \multicolumn{2}{|c|}{ maPi- $\Sigma$} & \multicolumn{2}{|c|}{$k a-\eta-\Sigma$} & $N-\Sigma$ \\
\hline
\end{tabular}

Whether or not this additional etymology is real, the center of innovation of the general antipassive-to-first-person-object development seems to be clearly in the southernmost languages of the Kirant. The developments do not seem to be very old, dating back to perhaps no more than a couple of hundred years, since they are not completed in all languages and/or have affected subbranches only partially (e.g., excluding Bantawa and Northwestern Camling from Southern Central Kiranti, and excluding the Mulgāũ Chintang varieties, along with perhaps other languages, from Eastern Kiranti).

\section{Explanations: natural forces and historical contingency in interaction}

The micro-areal developments described in the preceding can be best explained by the specific ways in which natural ('functional') trends interact with the history of the Southern Kirant. We first discuss the functional trends and then their interaction with local history.

Although we are not aware of systematic worldwide surveys to back this up, it seems reasonable to assume that it is a natural development for first person non-singular pronouns or agreement markers to be replaced by expressions for generic 'people', 'all' and similar notions. Such cases have been noted in several places (the best known being French on as a replacement for first person subjects; for others see Siewierska 2004: 211), although it is not clear how frequent such developments are. The conceptual link is confirmed by developments in the 
opposite direction, where first person forms are used for generic or impersonal reference. This development is fairy common in European languages (e.g., English we wouldn't do this for one wouldn't do this) and also attested occasionally elsewhere, indeed also in the Kirant, e.g., in Hayu (Michailovsky 1988: 173), Limbu (van Driem 1987: 218-221), or Belhare (Bickel 2003). Another parallel to this is the use of passives for first person A reference in Yakkha mentioned in Section 3.3 above.

The Southern Kiranti developments can be seen as specific instantiations of this pattern, linked to antipassivization and thereby to a use of generic expression for first person objects rather than subjects. This more specific pattern is also occasionally attested in other parts of the world: Matses (Fleck 2006) in South and Comanche (Charney 1993) in North America, Chukchi (Dunn 1999) in Siberia and Karen (Jones 1961) in Southeast Asia. ${ }^{5}$

Since the worldwide distribution of the general pattern goes across sociogeographically and areally completely disparate regions, the broad pattern of development from generic to first person reference is likely to be a natural, functionally motivated pathway that is spontaneously taken by languages, although perhaps not with high pressure. What remains to be explained is (i) the ultimate source and motivation of the development in conceptual terms, (ii) the fact that it is found not as a single instance in the Kirant but as a case of multiple parallel developments in a micro-area, and (iii) the fact that this micro-area is centered on the southernmost languages. For these questions, we turn to the specific sociolinguistic history of the Southern Kirant.

A likely trigger of the specific developments in the Southern Kirant is contact with politeness phenomena found in Maithili, the socially dominating IndoAryan language spoken to the South of the Kirant. This is based on two findings. First, Maithili displays a morphological feature of avoiding explicit reference to first persons, especially in socially prestigious varieties. Second, there is historiographic evidence for contact between southern Kiranti languages and these highprestige varieties of Maithili. We take up these two issues in turn.

Maithili verb agreement shows systematic avoidance of forms that could be unambiguously interpreted as referring to a first person. One manifestation of this is a systematic conflation between first and second person honorific forms in both intransitive and transitive constructions:

5 This is based on an informal survey of 200 languages that Bickel conducted in 2008. Help from student assistants Tyko Dirksmeyer, Thomas Goldammer and Jenny Seeg is gratefully acknowledged. The Chukchi and Karen parallels were also noted by Ebert (1991) and Ebert (1998), respectively. 
(12) Maithili (Bickel et al. 1999)
a. daur-l-aũh
run-PST-1/2HON
'I ran.' or 'You (honorific) ran.'
b. dekh-l-i
see-PST-1/2HON.TRANS
'I saw you.' or 'You (honorific) saw me.'

The forms can be disambiguated by personal pronouns but there is often no need for this in actual discourse, and the use without such pronouns is in fact a strategic choice for avoiding overt reference. Bickel et al. (1999) explain this by positing a face-saving constraint that overrides competing principles from empathydriven trends to register first person participants. Face-saving constraints are of course a key dimension of politeness effects (Brown and Levinson 1987), and this is why the constraint in Maithili is operative especially in varieties associated with polite and formal style.

In Maithili, the forms in (12) critically involve conflation with second person honorific reference, not others. This directly follows from politeness principles of indexing higher status referents whenever possible (Bickel et al. 1999). For the Southern Kiranti languages we are not aware of any direct linguistic coding of social status, and not of any grammaticalized coding by honorifics. ${ }^{6}$ Therefore, we expect the relevant politeness constraint only to have an impact on the treatment of speakers. If we assume that such constraints were, or still are, operative in Kiranti societies, we obtain a plausible explanation for the development of antipassives into first person object forms: antipassives fulfill the constraints because they avoid unique identification of the speaker by substituting speaker reference by generic or no reference.

The constraints were apparently relevant only for object arguments, not subject arguments. This is different from Maithili, but it can be explained by the way object agreement functions in discourse in Kiranti languages and by a special cultural value attributed to first person objects. First, we note that object agreement frequently refers specifically to recipient roles. Extrapolating from a detailed analysis of Chintang (Schikowski et al. in press), ${ }^{7}$ it appears that a salient

\footnotetext{
6 The only Kiranti language that is known to us to have developed honorific pronouns is the Northwestern language Thulung (Lahaussois 2003). The development seems to be recent. 7 We assume that the frequency patterns of Chintang are fairly representative of other Southern and Eastern Kiranti languages, and this is confirmed by impressionistic surveys of texts. Note that we report here counts for first person objects only, whereas Schikowski et al. (in press) report counts on all objects.
} 
proportion of first person object agreement is with recipient arguments (manifesting itself in what is known as primary object alignment): in Chintang this accounts for $70 \%$ of object agreement in three-place predicates. Even when compared to all cases of first person object agreement, including two-place predicates, recipient agreement still takes up a remarkable share of about one third, including conceptually important verb classes like all verbs of giving and talking that involve human object referents.

Second, the ethnographic record suggests that recipients are of special concern for politeness in Kiranti societies, and this special concern appears to have overruled the presumably universal concern for first person agents and first person intransitive subjects: transactions of giving and receiving are of key importance, especially in the context of marriage (e.g., requests by intermediaries, gift-giving, ceremonial dialogues for the transfer of rights between wife-givers and wife-takers), but also in the context of ordinary economic as well as sacrificial exchange (Gaenszle 2002: 140). In all these situations a petitioner typically puts forward a request, accompanied by gifts, and putting the addressee in a higher, powerful position as a potential giver. As the petitioner expresses his plea, e.g., "Give us your daughter in marriage!", he is likely to stress the role of the giver and to minimize the role of the recipient. In Mewahang and Belhare ceremonial dialogues, for example, the wife-takers address the wife-givers as maiti rājā 'wife-giver king' and minimize their own role as ignorant people who do not know how to even speak properly (Gaenszle 2002: 203-210). Thus the force of the imposition on the addressee's negative face is reduced, stressing his positive face as a powerful and respected being. Of course, as soon as the addressee accepts the gifts, this puts him under the moral obligation to reciprocate and give what the petitioners request.

Against this background, it is likely that the developments of antipassives into first person object markers was brought into Kiranti by copying a politeness strategy of self-effacement from Maithili and applying it in those situations where it mattered most for traditional concerns, i.e., for recipients. Evidence for such a copy scenario comes from political developments in exactly the time frame of about 200-300 years ago that seems reasonable to assume for the linguistic developments (cf. above): Since at least the 16th century parts of the southernmost Kiranti people maintained a special political relationship with royal dynasties in the Tarai, the sub-Himalayan plains of today's Nepal. The exact origin of the first known of these kings (Vijayanārayan, who established Vjayapur near present-day Dharan, cf. Map 1) is controversial, but all evidence points to strong affiliations with dynasties that were culturally embedded in the larger (East) Indian context. By the end of the 16th century, the Eastern Tarai region came under the influence of the Indo-Aryan ("Rajput”) Sen dynasty, which had expanded from Pālpā to 
Makvānpur and eventually included the Tarai principalities of Udayapur, Caudandi and Vijayapur (Pradhan 1991, Gaenszle 2000). During that period, some of the Sen rulers, who controlled the plains including much of Mithila, the center of the Maithili language, entered a military alliance with Kiranti chiefs controlling the adjacent territories in the north whom they gave the hereditary position of cautariy $\bar{a}$, i.e., prime minister. The points of contact were likely limited to the social elites at the court, but as such, they also increased the borrowing of religious traditions, leading to the modern 'hybrid' patterns of ritual and religion that is characteristic especially of southern Kiranti societies (Gaenszle et al. 2005). The intense relationship with the Sen courts lasted until the Gorkha (Nepali) conquests at the end of the 18th century.

Crucially, the language used at the Sen courts for official purposes was Maithili, and even letters addressed to the Kiranti chiefs were written in this language (Pradhan 1991: 48, 83, 222). This makes it likely that Maithili, and especially the high-caste, socially prestigious style used in the court, became a prestige language for southern Kiranti elites, perhaps comparable to the role that French played at about the same time in Europe. As a result of this, the Kiranti are likely to have borrowed the socially most distinctive aspect of this style, viz. the strong patterns of reference avoidance as a face-keeping strategy. And given the indigenous ideas of the recipient's face and delicate social status described above, it was natural to adopt the Maithili style specifically for object reference.

This scenario predicts that other contact effects were limited and did not extend to areas which one would expect to be affected in situations of mass bilingualism, such as large parts of the lexicon or constructional calques in substantial numbers. This prediction is borne out: Maithili loanwords and loanwords from other Indo-Aryan languages in the south are relatively rare. Apart from Limbu məna mona, Puma mınna 'person' and Puma jhara 'all' mentioned above, loanwords seem to be limited to a few culinary items (e.g., Limbu harrundi, Puma/Chintang hardi 'turmeric, curcuma' $\prec$ Maithili hardī vs. Nepali besār; Chintang, Belhare marci, Yakkha macchi $\prec$ Maithili marcāi 'chilli' vs. Nepali khorsāni ) and words for objects of wealth and prestige, in particular certain terms which have entered the ritual language: Chintang arawa 'unparched and husked rice' ( $\prec$ Maithili arawā vs. Nepali aluwā); Chintang and Puma sona rupa 'gold and silver' ( $\prec$ Maithili sona + Maithili rūpā); Chintang guwari 'areca nut' ( $\prec$ Maithili gūā vs. Nepali supāri). This is precisely the lexical layer one would expect to be affected under the proposed sociolinguistic scenario. 


\section{Conclusions}

When diachronic developmental patterns are found in different, sociogeographically completely unrelated parts of the world, they are likely to be caused by natural, functionally motivated forces of language change. But a full understanding of the developments requires an account of the precise variants found and their local distribution and historical background. The present case study exemplifies these general observations: for the development of first person object agreement in some Kiranti languages, we showed that while following a functionally motivated pattern, the precise characteristics and areal distribution of the development is best understood against the political history of the region.

Acknowledgments: We thank Robert Schikowski for useful comments on an earlier draft and for help performing the corpus counts reported in Section 4. We are also grateful to Shobana Chelliah for helpful suggestions on the final draft and to Ross Purves for geo-coding a set of map polygons for us. Part of our research was funded by Grant No. II/79092 from the Volkswagen Foundation.

\section{References}

Bickel, Balthasar. 1996. Aspect, mood, and time in Belhare. Zürich: ASAS.

Bickel, Balthasar. 1997. Spatial operations in deixis, cognition, and culture: Where to orient oneself in Belhare. In Jan Nuyts and Eric Pederson (eds.), Language and conceptualization, 46-83. Cambridge: Cambridge University Press.

Bickel, Balthasar. 2000. Deictic transposition and referential practice in Belhare. Journal of Linguistic Anthropology 10. 224-247.

Bickel, Balthasar. 2003. Belhare. In Graham Thurgood and Randy J. LaPolla (eds.), The Sino-Tibetan languages, 546-570. London: Routledge.

Bickel, Balthasar. 2004. Hidden syntax in Belhare. In Anju Saxena (ed.), Himalayan languages: Past and present, 141-190. Berlin: Mouton de Gruyter.

Bickel, Balthasar. 2011. Multivariate typology and field linguistics: A case study on detransitivization in Kiranti (Sino-Tibetan). In Peter K. Austin, Oliver Bond, David Nathan and Lutz Marten (eds.), Proceedings of the Conference on Language Documentation and Linguistic Theory 3, 3-13. London: SOAS.

Bickel, Balthasar, Goma Banjade, Martin Gaenszle, Elena Lieven, Netra Paudyal, Ichchha P. Rai, Manoj Rai, Novel K. Rai and Sabine Stoll. 2007a. Free prefix ordering in Chintang. Language 83. 43-73.

Bickel, Balthasar, Walter Bisang and Yogendra P. Yãdava. 1999. Face vs. empathy: The social foundations of Maithili verb agreement. Linguistics 37. 481-518.

Bickel, Balthasar, Martin Gaenszle, Arjun Rai, Prem Dhoj Rai, Shree Kumar Rai, Vishnu S. Rai and Narayan P. Sharma (Gautam). 2007b. Two ways of suspending object agreement in 
Puma: Between incorporation, antipassivization, and optional agreement. Himalayan Linguistics 7. 1-18.

Bickel, Balthasar and Johanna Nichols. 2003. Typological enclaves. Paper presented at the 5 th Biannual Conference of the Association for Linguistic Typology, Cagliari, September 18; available at http://www.uzh.ch/spw/autotyp/download.

Bickel, Balthasar and Johanna Nichols. 2005a. Inclusive/exclusive as person vs. number categories worldwide. In Elena Filimonova (ed.), Clusivity, 47-70. Amsterdam: Benjamins.

Bickel, Balthasar and Johanna Nichols. 2005b. Inflectional synthesis of the verb. In Martin Haspelmath, Matthew S. Dryer, David Gil and Bernard Comrie (eds.), The world atlas of language structures, 94-97. Oxford: Oxford University Press.

Brown, Penelope and Stephen C. Levinson. 1987. Politeness: Some universals in language use. Cambridge: Cambridge University Press.

Charney, Jean Ormsbee. 1993. A grammar of Comanche. Lincoln: University of Nebraska Press. Chelliah, Shobhana L. 1997. A grammar of Meithei. Berlin: Mouton de Gruyter.

Doornenbal, Marius. 2009. A grammar of Bantawa: University of Leiden PhD dissertation. van Driem, George. 1987. A grammar of Limbu. Berlin: Mouton de Gruyter.

van Driem, George. 1990. The fall and rise of the phoneme / $r$ in Eastern Kiranti: Sound change in Tibeto-Burman. Bulletin of the School of Oriental and African Studies 53. 83-86.

van Driem, George. 2001. Languages of the Himalayas. Leiden: Brill.

Dunn, Michael J. 1999. A grammar of Chukchi. Canberra: Australian National University PhD dissertation.

Ebert, Karen H. 1991. Inverse and pseudo-inverse prefixes in Kiranti languages: Evidence from Belhare, Athpare and Dungmali. Linguistics of the Tibeto-Burman Area 14. 73-92.

Ebert, Karen H. 1997a. Camling (Chamling). München: LINCOM.

Ebert, Karen H. 1997b. A grammar of Athpare. München: LINCOM.

Ebert, Karen H. 1998. Marking of 1st and 2nd person patient in verbal paradigms: Some material for an areal survey. Handout of paper given at the Meeting of the European Cooperation Project on Himalayan Languages, Heidelberg, June 4-6, 1998.

Ebert, Karen H. 1999. The up-down dimension in Rai grammar and mythology. In Balthasar Bickel and Martin Gaenszle (eds.), Himalayan space: Cultural horizons and practices, 109-140. Zürich.

Fleck, David W. 2006. Antipassives in Matses. Studies in Language 30. 541-573.

Gaenszle, Martin. 2000. Origins and migrations: Kinship, mythology, and ethnic identity among the Mewahang Rai of East Nepal. Kathmandu: Mandala Book Point.

Gaenszle, Martin. 2002. Ancestral voices: Oral ritual texts and their social contexts among the Mewahang Rai in East Nepal. Münster: LIT Verlag.

Gaenszle, Martin, Balthasar Bickel, Goma Banjade, Elena Lieven, Netra Paudyal, Ichchha P. Rai, Manoj Rai, Novel K. Rai and Sabine Stoll. 2005. Worshipping the king god: A preliminary analysis of Chintang ritual language in the invocation of Rajdeu. In Yogendra P. Yadava, Govinda Bhattarai, Ram Raj Lohani, Balaram Prasain and Krishna Parajuli (eds.), Contemporary issues in Nepalese linguistics, 33-47. Kathmandu: Linguistic Society of Nepal.

Jones, Jr., Robert B. 1961. Karen linguistic studies. Berkeley: University of California Press. Lahaussois, Aimée. 2003. Thulung Rai. Himalayan Linguistics Archive 1. 1-25.

Matisoff, James A. 2003. Handbook of Proto-Tibeto-Burman: System and philosophy of Sino-Tibetan reconstruction. Berkeley: University of California Press.

Michailovsky, Boyd. 1988. La langue hayu. Paris: CNRS. 
Michailovsky, Boyd. 1994. Manner vs. place of articulation in the Kiranti initial stops. In Hajime Kitamura, Tatsuo Nishida and Yasuhiko Nagano (eds.), Current issues in Sino-Tibetan linguistics, 766-772. Osaka: National Museum of Ethnology.

Michailovsky, Boyd. 2001. Limbu nous autres and First Person morphology. Linguistics of the Tibeto-Burman Area 24. 145-156.

Michailovsky, Boyd. 2007. Pronominally marked noun determiners in Limbu. In Roland Bielmeier and Felix Haller (eds.), Linguistics of the Himalayas and beyond, 189-202. Berlin: Mouton de Gruyter.

Nichols, Johanna. 1997. Modeling ancient population structures and population movement in linguistics and archeology. Annual Review of Anthropology 26. 359-384.

Nichols, Johanna and Balthasar Bickel. 2005. Possessive classification and obligatory possessive inflection. In Martin Haspelmath, Matthew S. Dryer, David Gil and Bernard Comrie (eds.), The world atlas of language structures, 242-245. Oxford: Oxford University Press.

Opgenort, Jean Robert. 2004. A Grammar of Wambule. Leiden: Brill.

Pradhan, Kumar. 1991. The Gorkha Conquests. Calcutta: Oxford University Press.

Rai, Novel K. 1988. The locative marker suffixes of Bantawa and their extension. Arbeitsberichte aus dem Seminar für Allgemeine und Indogermanische Sprachwissenschaft der Universität Kiel 11. 130-135.

Schackow, Diana. 2014. A grammar of Yakkha. University of Zürich PhD dissertation.

Schikowski, Robert. 2013. Object-conditioned differential marking in Chintang and Nepali. University of Zürich PhD dissertation.

Schikowski, Robert, Netra P. Paudyal and Balthasar Bickel. In press. Flexible valency in Chintang. In Bernard Comrie and Andrej Malchukov (eds.), Valency classes: A comparative handbook, Berlin: Mouton de Gruyter [pre-print available at http://www.spw.uzh.ch/clrp/ downloads/schikowski-chintang-valency.pdf].

Siewierska, Anna. 2004. Person. Cambridge: Cambridge University Press.

Starostin, Sergej. 1998. Kiranti etymology. StarLing Database server; http://starling.rinet.ru/ cgi-bin/main.cgi?flags=eygtnnl (accessed September 29, 2005). 